\title{
Global variation of meteor trail plasma turbulence
}

\author{
L. P. Dyrud ${ }^{1}$, J. Urbina ${ }^{2}$, J. T. Fentzke ${ }^{1}$, E. Hibbit ${ }^{2}$, and J. Hinrichs ${ }^{2}$ \\ ${ }^{1}$ Applied Physics Laboratory, John Hopkins University, Columbia, MD, USA \\ ${ }^{2}$ Communications and Space Sciences Laboratory, Pennsylvania State University, University Park, PA, USA
}

Received: 15 March 2011 - Revised: 29 November 2011 - Accepted: 1 December 2011 - Published: 16 December 2011

\begin{abstract}
We present the first global simulations on the occurrence of meteor trail plasma irregularities. These results seek to answer the following questions: when a meteoroid disintegrates in the atmosphere, will the resulting trail become plasma turbulent? What are the factors influencing the development of turbulence? and how do these trails vary on a global scale? Understanding meteor trail plasma turbulence is important because turbulent meteor trails are visible as non-specular trails to coherent radars. Turbulence also influences the evolution of specular radar meteor trails; this fact is important for the inference of mesospheric temperatures from the trail diffusion rates, and their usage for meteor burst communication. We provide evidence of the significant effect that neutral atmospheric winds and ionospheric plasma density have on the variability of meteor trail evolution and on the observation of non-specular meteor trails. We demonstrate that trails are far less likely to become and remain turbulent in daylight, explaining several observational trends for non-specular and specular meteor trails.
\end{abstract}

Keywords. Space plasma physics (Ionization processes; Numerical simulation studies; Turbulence)

\section{Introduction}

The daily occurrence of billions of meteor trails in the Earth's upper atmosphere presents a powerful opportunity to use remote sensing tools to better understand the meteoroids that produced them, and the atmosphere and ionosphere in which their trails occur. One of the most promising tools employed in this endeavor are high-power-large-aperture (HPLA) radars. Such radars routinely observe two distinct types of meteor echoes: head echoes and non-specular meteor trails. Head echoes are radar reflections from targets

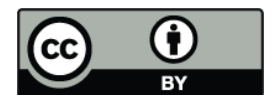

Correspondence to: L. P. Dyrud (lars.dyrud@jhuapl.edu) with short durations, usually less than $1 \mathrm{~ms}$ at a given range, and moving at apparent meteoroid velocities (Close et al., 2002; Janches et al., 2000, 2006; Mathews et al., 2001; Chau and Galindo, 2008; Dyrud et al., 2008). When the radar is pointed perpendicular to the Earth's magnetic field, head echoes are often, but not always, followed by echoes lasting seconds to minutes (Dyrud et al., 2005a, b; Zhou et al., 2001; Malhotra et al., 2007a, b). Because these echoes occur simultaneously over multiple radar range gates, the term non-specular echoes has been adopted by many authors in order to differentiate them from echoes detected with specular meteor radars, which require that the trail be aligned perpendicular to the radar $\boldsymbol{k}$ vector (Ceplecha et al., 1998; Cervera and Elford, 2004). It is now understood that non-specular trails are reflections from plasma instability generated from field-aligned irregularities (FAI) (Chapin and Kudeki, 1994a; Oppenheim et al., 2000; Zhou et al., 2001; Dyrud et al., 2001, 2002, 2007; Close et al., 2008). However, the influence that turbulence has on specular observations of meteor trails has only been briefly studied (Hocking, 2004; Galligan et al., 2004), and we do not yet understand the degree to which meteor trails are inherently plasma unstable. This paper seeks to address some of these unknowns.

We focus on the role that neutral atmospheric wind and ionospheric plasma density have on the development of meteor trail turbulence and its evolution. Our goal is to understand how regional, diurnal, and seasonal variability in these background parameters will influence the role that turbulent meteor trails have on various applications and scientific studies. Most prominently, turbulent trails are thought to have a diffusion rate that can exceed the nominal crossfield ambipolar diffusion rate by up to an order of magnitude, significantly altering trail evolution, duration, and radar reflectivity (Dyrud et al., 2001). The effects of this turbulent evolution are important for specular radar derivations of diffusion rate and therefore neutral temperature $\left(T_{\mathrm{n}}\right)$ (Hocking, 1999; Kumar, 2007), meteor burst communication (Fukuda et al., 2003), and scientific studies of meteors and the upper

Published by Copernicus Publications on behalf of the European Geosciences Union. 
atmosphere involving non-specular trail observations in general (Dyrud et al., 2005a, b, 2007; Malhotra et al., 2007a, b).

In order to understand the global variation of meteor trail turbulence, we expanded a model of the evolution of an individual meteor from atmospheric entry to trail instability and diffusion (see Dyrud et al., 2005a, b, 2007, for a detailed description of the model) by incorporating climatological models for the relevant ionospheric and atmospheric parameters. For readers interested in the global modeling of the incoming meteor flux see Janches et al. (2006) and Fentzke and Janches (2008).

Our model was originally used to simulate artificial radar range-time-intensity (RTI) images for comparison with facilities like the $50 \mathrm{MHz}$ Jicamarca Radar, where interferometeric measurements of meteors are regularly undertaken (Chau et al., 2007) as well as other coherent radars (Chau and Galindo, 2008; Urbina et al., 2000; Dyrud et al., 2005a, 2007; Hinrichs et al., 2009). This program simulates head echoes and non-specular trails for meteoroids of a chosen velocity, mass, and composition that enter the Earth's atmosphere. Our new program runs this individual meteor model, and evaluates several key parameters pertaining to trail plasma instability. In this paper, we focus on the duration of trail plasma instability, which is closely associated with the duration of an individual non-specular trail observation. Further, duration also acts as a guide for researchers interested in specular meteor trail observations, and meteor burst communication, by indicating when, where, and to what degree they can expect turbulent versus laminar meteor trail evolution. By analyzing trail variation on a global scale, we show that properties of the atmosphere and ionosphere play a critical role in the observation and interpretation of meteor trail observations, and that as a result, the characteristics of meteor trail evolution are considerably more variable than previously expected.

\section{Model description}

The model simulates meteoroid entry into the atmosphere, including ablation, ionization, thermal expansion and plasma stability based upon the meteor Farley-Buneman GradientDrift (FBGD) instability (Dyrud, 2001, 2002; Oppenheim et al., 2000, 2003a, b). The program can automatically take as input variables: location, time, and specific ionospheric and atmospheric data from three main climatological models: Committee on Space Research (COSPAR): The COSPAR International Reference Atmosphere (CIRA-05), the International Reference Ionosphere (IRI2000) (Bilitza, 2001), and the Horizontal Wind Model (HWM) (Hedin et al., 1996). The parameters required from these models include electron density, atmospheric mass density, neutral temperature and wind speed, and from these we also derive ion and electron collision frequencies based upon the formulas from Banks and Kockarts (1972) for a given location and time. This in- formation is used to make location specific meteor simulations, which are then called multiple times to build up global maps of meteor trail characteristics. While we recognize that these climatological models do not capture the day-today variability of aeronomical and ionospheric parameters, they do allow for an examination of the resulting climatological and global variation expected for meteor trail evolution. Until now this topic has never been explored, particularly in light of the known influence of plasma turbulence.

An example of non-specular trail comparisons between observation and modeling results is displayed in Fig. 1. We show the results of this model as a simulated range-timeintensity (RTI) image of a head echo and non-specular trail, similar to those produced by coherent radar observations (Chapin and Kudeki, 1994a, b; Close et al., 2002; Oppenheim et al., 2008; Dyrud al., 2005a, b; Malhotra et al., 2007a, b). This figure displays the head echo trace as a diagonal colored line, with color corresponding to the trail electron line density per meter divided by $10^{6}$, such that it may appear on the same color bar as the FBGD growth rate shown in the non-specular trail portion of the RTI plot that appears after the head-echo. We have developed numerous head echo models (see Dyrud and Janches, 2008) and have opted to plot a parameter which is related to head echo strength, but is also of direct physical relevance to the development of plasma instability in the trail. To the right of the head echo, this plot displays the calculated, non-negative, FBGD growth rate as a function of time and altitude for a diffusing meteor column. Examination of Fig. 1 reveals that only a limited altitude portion of the trail is immediately plasma unstable, with the width of this unstable portion decreasing in time. The total duration of plasma instability for this example is approximately $15 \mathrm{~s}$, which is defined as the time from trail generation at a given altitude to the time the growth rate becomes negative at that same altitude. The duration and altitude of the observed and simulated meteor trails are similar, and this was achieved by using the climatological neutral winds, densities and electron densities for this location and time and a meteoroid with a $20 \mu \mathrm{g}$ mass, traveling at $55 \mathrm{~km} \mathrm{~s}^{-1}$ with a zenith angle of $45^{\circ}$. The observations displayed in Fig. 1 are from Fort Macon, North Carolina and were obtained in a campaign during June 2001 (Hibit, 2010). Note that the apparent signal observed by the radar below approximately $97 \mathrm{~km}$ in the right panel results from the decoding process.

\section{Global model results}

In this section, we examine the duration of meteor trail turbulence as a function of geographic location, for a trail produced by a $10 \mu \mathrm{g}$ and $1 \mu \mathrm{g}$ meteor traveling at $55 \mathrm{~km} \mathrm{~s}^{-1}$ on 1 January 2001 at 00:00 UT, with a zenith angle of $45^{\circ}$. These characteristic meteoroid parameters were chosen because this is a commonly measured size class of meteoroids among the billions of daily meteors (Mathews et al., 2001; 

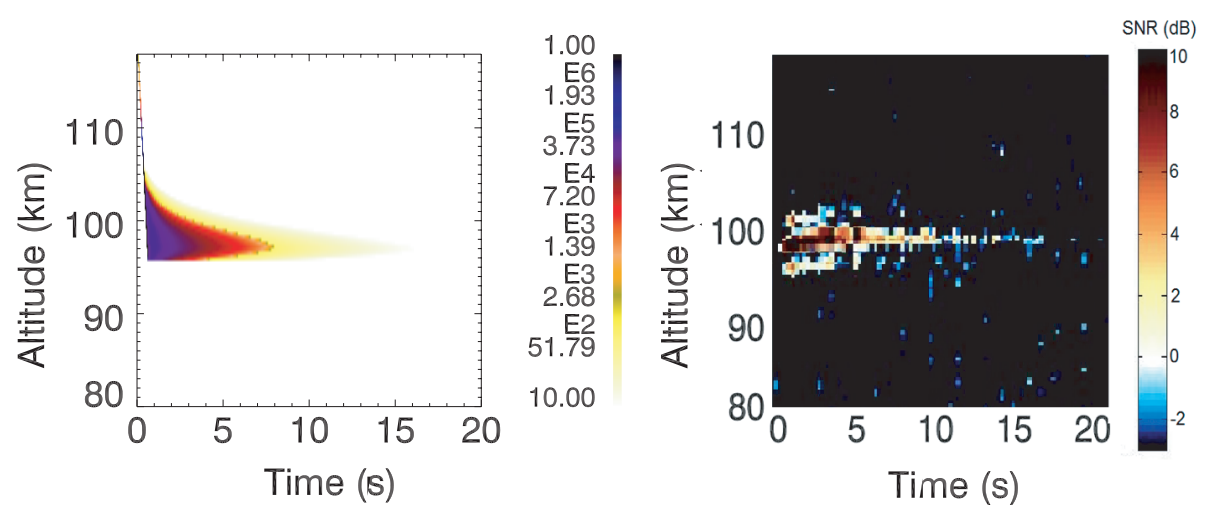

Fig. 1. In the left panel, a simulated head-echo and non-specular trail for a meteoroid entering at the time and geographic location of an observed meteor in North Carolina $\left(35^{\circ} \mathrm{N}, 76^{\circ} \mathrm{W}\right)$ using the Univ. of Illinois radar operated at Fort Macon (right panel). The meteor was recorded near 00:00 UT, on 27 June 2001. The simulated meteoroid mass is $20 \mu \mathrm{g}$, traveling at a velocity of $55 \mathrm{~km} \mathrm{~s}^{-1}$ with a $45^{\circ}$ entry angle, composed of an atomic mass of 30 AMU (Chondritic type meteoroid). The duration of the trail turbulence is approximately $15 \mathrm{~s}$. The color bar on the left shows the instability growth rate in $\mathrm{s}^{-1}$ for the trail, and the simulated head echo electron line density per meter divided by $10^{6}$ (units chosen such that they appear on the same scale). The range-time-intensity (RTI) portion of the non-specular trail on the right side of the figure has the same altitude and time range as the simulation, with the color bar representing SNR.

Dyrud and Janches, 2008). The meteor simulation of the type shown in Fig. 1 is repeated several hundred times across a $5^{\circ}$ latitude and longitude grid, with the analyzed results displayed in Fig. 2a. This plot shows, in color, the duration of plasma instabilities within the meteor trail for each location, these durations are shown to vary in the range from 0 to approximately $35 \mathrm{~s}$. Where 0 indicates that no trail turbulence is generated. The first striking observation from this figure is the dramatic global variation of meteor trail evolution, even for trails produced by the very same meteoroid. Some of the features shown are: a clear day to night variation, i.e., that duration is significantly longer in the dark regions of the globe, and since we show a January day one can see that more of the Northern Hemisphere contains longer turbulent durations than the more sunlit Southern Hemisphere. We also see that that duration is in general longer near equatorial regions with enhancements that appear in the Northern Atlantic Ocean, over South America and Africa. The variation in this figure is caused by variation in the main drivers for instability, which are primarily background ionization levels, and the magnitude of the neutral wind blowing both perpendicular to the trail and the geomagnetic field.

We point out here that only the HWM was used for determination of winds at typical meteor altitudes, and therefore the climatogical HWM results will likely vary to a larger extent at the equator and at the highest latitudes where ionospheric drifts due to electrojets dominate the neutral winds. Hinrichs et al. (2009), has specifically analyzed a 24-h meteor simulation for the radar located at Jicamarca with the inclusion of an electrojet drift model to show that the magnitude of the electrojet drift strongly modulates trail duration. We note that in the future we expect to incorporate climatological models for the high and low latitude electrojets into this global simulator. The magnetic field model used for our simulations is the IGRF model. We note that this has a very minor effect on the potential development of turbulence (Dyrud et al., 2001). Currently, we are modeling the inherent physics of instability generation based on growth rate, but in the future we hope to include the effects of different observing geometries to future refine our modeling capability, which will require modeling the angle of the radar to the geomagnetic field. We continue with a presentation of both the meteoric and atmospheric parameters responsible for variability in meteor trail evolution.

\section{Meteor properties}

We now investigate meteor properties and their influence on meteor trail duration. The two meteor properties that have the greatest effect on meteor trail duration are mass and velocity. Figure $2 b$ is a global simulation with identical parameters as $2 \mathrm{a}$ except the mass of the meteor has been decreased from $10.0 \mu \mathrm{g}$ to $1.0 \mu \mathrm{g}$ in order to investigate the effect of mass. As seen by comparing Fig. $2 \mathrm{a}$ and $\mathrm{b}$, a meteor with a mass of $10.0 \mu \mathrm{g}$ will produce longer duration meteor trails compared to a meteor with a smaller mass. A more massive meteor produces steeper plasma density gradients, and penetrates to lower altitudes where polarization fields are the strongest. Steeper plasma density gradients generate stronger ambi-polar electric field thereby increasing instability growth rate. Qualitatively, the meteor FBGD instability is similar to the FBGD instability responsible for auroral and equatorial electrojet radar echoes and becomes unstable when the electron drift (gradient and $\boldsymbol{E} \times \boldsymbol{B}$ drift) speed exceeds a modified ion acoustic speed; the reader is referred to Dyrud et al. (2007) for a more detailed discussion. Not only do 

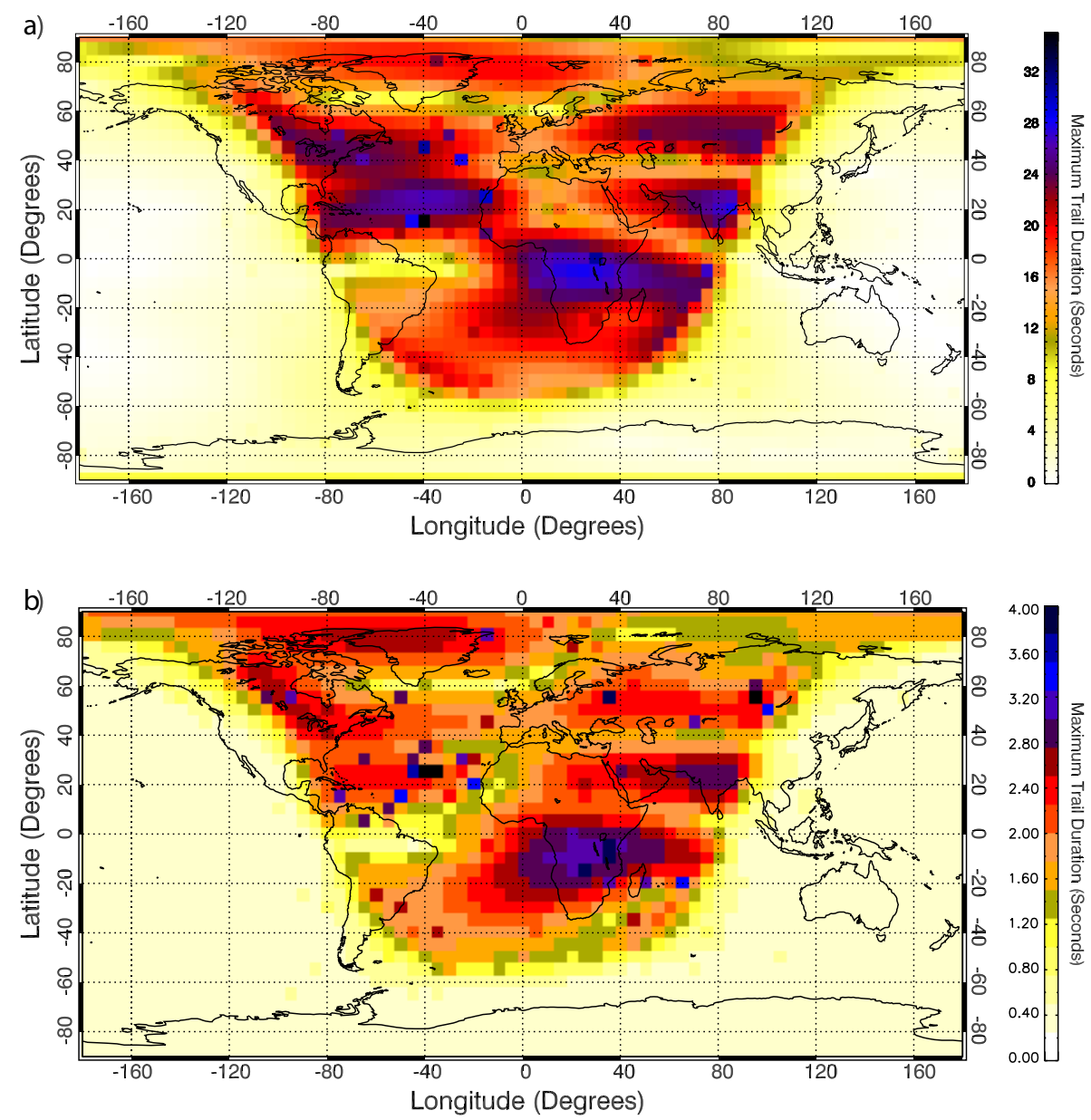

Fig. 2. (a) A global simulation of the duration of meteor trail turbulence of a single $10.0 \mu \mathrm{g}$ meteor simulated on all the world grid points separated by $5^{\circ}$, traveling at $55 \mathrm{~km} \mathrm{~s}^{-1}$ with a $45^{\circ}$ entry angle at 00:00 UT on 1 January. The units of the color bar are in seconds after meteor trail creation. Each pixel results from the measured duration of a simulation of the type shown in Fig. 1. Panel (a) illustrates the combined influences of the background atmospheric properties: electron density and horizontal wind speed on a meteor's trail duration. (b) A global simulation of the duration of meteor trail turbulence, but for a $1 \mu \mathrm{g}$ meteor simulated for all global grid points, again traveling at $55 \mathrm{~km} \mathrm{~s}{ }^{-1}$ with a $45^{\circ}$ entry angle at 00:00 UT on 1 January. The units of the color bar are in seconds after meteor trail creation. Again, each pixel results from the measured duration of a simulation of the type shown in Fig. 1. Notice that a meteor of lesser mass experiencing the identical atmospheric parameters as panel (a) will produce meteor trails of shorter duration or no meteor trail at all depending on the location and sunlit conditions.

meteors of larger mass result in longer duration meteor trails at night, but during daytime hours as well. These meteors with higher masses are now turbulent in regions where the $1 \mu \mathrm{g}$ meteors were not.

Unlike mass, an increased meteor velocity doesn't always have a complementary effect that increases meteor trail duration. However, Fig. 3 shows the drastic effect velocity has on meteor trails' durations. For example, a slow meteor traveling at $15 \mathrm{~km} \mathrm{~s}^{-1}$ has less ablation and ionization, which produces a relatively short lived meteor trail, if any trail at all. A very fast meteor traveling at $55 \mathrm{~km} \mathrm{~s}^{-1}$ has so much energy that all of its mass becomes ionized at such high altitudes that short trails are produced, due to weak polarization fields above $\sim 100 \mathrm{~km}$, and more rapid trail diffusion. Based upon our modeling effort we find that the longest meteor trails observed are created by meteors of speeds in between both extremes. A velocity ranging from $25-35 \mathrm{~km} \mathrm{~s}^{-1}$ allows the meteor to reach lower altitudes where polarization electric fields become stronger, yet still generate steep density gradients (see Dyrud et al., 2007, for discussion). The impact that meteor velocity has on global meteor trail variability is shown by comparing Figs. $2 \mathrm{~b}$ and 4 . Figure 4 shows a global simulation of a $1 \mu \mathrm{g}$ meteoroid, identical to that in Fig. $2 \mathrm{~b}$, but with a velocity of $35 \mathrm{~km} \mathrm{~s}^{-1}$ entering at $45^{\circ}$. One may see that the slower velocity results in longer duration trails and more daytime trails. 


\section{Atmospheric properties}

In order to understand the atmosphere's role in meteor trail evolution we investigate the parameters that have the most profound effects on trail evolution. We find that these parameters are: the ionospheric electron density and the horizontal winds that are present at meteor ablation altitudes. Small changes in atmospheric properties result in dramatic global variability. Since electron density and winds also affect meteor trail duration, we must further investigate the variability seen in these parameters to understand the global meteor trail outlook.

First, we investigate the influence of electron density as its effect on trail duration is quite evident, as seen in the day/night variability of trail duration shown in the global simulations. Electron density is important because densities in the day differ from nighttime densities by a factor of two or more and electron density directly effects meteor trail evolution and duration. A meteor immersed in high ionospheric electron densities will produce a shorter plasma turbulent trail than if lower densities were present. Figure 5 shows the electron density across the globe at $100 \mathrm{~km}$ for 1 January at 00:00 UT. The global structure of electron density determines the area across the globe in which conditions favor meteor trail evolution.

Electron density is an important factor in meteor trail evolution, but identical meteors that encounter constant electron density still have variability in trail duration around the globe. This is attributed to the winds that a meteor encounters. A meteor that is exposed to high winds will have a longer duration than the same meteor that is exposed to lower wind speeds. The impact that wind speed has on trail duration of meteors at different entry velocities is shown in Fig. 6. To demonstrate the effect that global winds have on meteor trail duration we examined the horizontal wind speed at the altitude where maximum duration of the meteor trail occurs (normally around $90 \mathrm{~km}$ ), this is shown in Fig. 7. In the figure wind speeds vary from $0.5 \mathrm{~m} \mathrm{~s}^{-1}$ to $100 \mathrm{~m} \mathrm{~s}^{-1}$. The wind speed at the altitude of maximum duration (around $90 \mathrm{~km}$ ) gives a good picture of the way winds directly influence a meteor's plasma trail. Both the distinct global structure of winds at the altitude of maximum duration and the diurnal cycle of electron density are essential in understanding the global variability presented in this paper.

\section{Seasonal variability}

The effects of the atmosphere on meteor trail evolution can be seen not only globally, but seasonally as well. We now look at seasonal variability of meteor trails and how they are influenced by the seasonal variation in atmospheric properties. To best capture seasonal variation we inspect the simulations near the equinox and solstice. Seasonal variability in meteor trail duration can be seen by comparing Figs. $2 \mathrm{~b}$

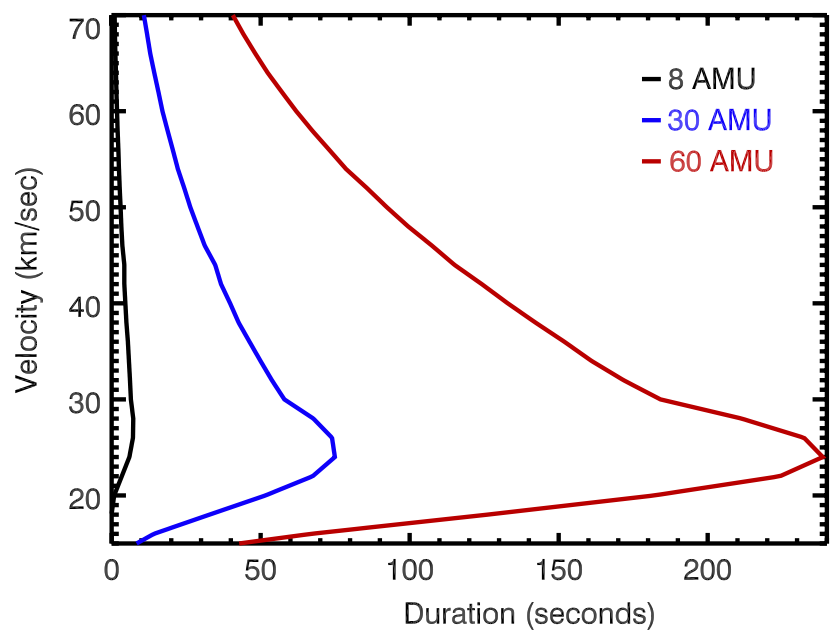

Fig. 3. The duration of 3 meteor trails of different atomic masses: 8, 30 and 60 AMU (representative of Oxygen, Chondrite and Iron compositions, respectively) for a variety of entry velocities. The duration of a meteor trail is plotted in seconds and the meteors' velocities in $\mathrm{km} \mathrm{s}^{-1}$ for a $10.0 \mu \mathrm{g}$ particle entering with $0^{\circ}$ entry angle with a background wind speed of $10 \mathrm{~m} \mathrm{~s}^{-1}$ wind.

and 8 . The obvious differences in the global plots of meteor trail duration for identical meteors on 1 January and 27 June are the result of subtle, yet key, changes in the atmosphere throughout the seasons.

One seasonal difference results from a shift in the structure of the global electron density. Figure 5 showed the global variation of electron density in winter for the Northern Hemisphere. The electron density distribution can change significantly throughout the seasons as it shifts based on the amount of sun present throughout the day at various latitudes. For example June's electron density is a horizontally flipped version of Fig. 5 since the night is present longer in the Southern Hemisphere. Since both hemispheres experience roughly the same amount of sunlight during the months near equinox, electron density will reflect accordingly. We note that the other main change in atmospheric structure influencing trail duration throughout the seasons is the horizontal winds that an entering meteor experiences. The structure and the magnitude of horizontal winds at the altitude of maximum duration changes throughout the year, due to the change that occurs in global circulation and dynamics.

The large difference seen in both day/night observations and seasonal variability of meteor trial measurements across the globe is largely explained by the combination of electron density, winds, and meteor properties. With this understanding we now have a much better knowledge about the role that seasonal variability in the structure of the atmosphere has on worldwide variability of meteor trail evolution. 


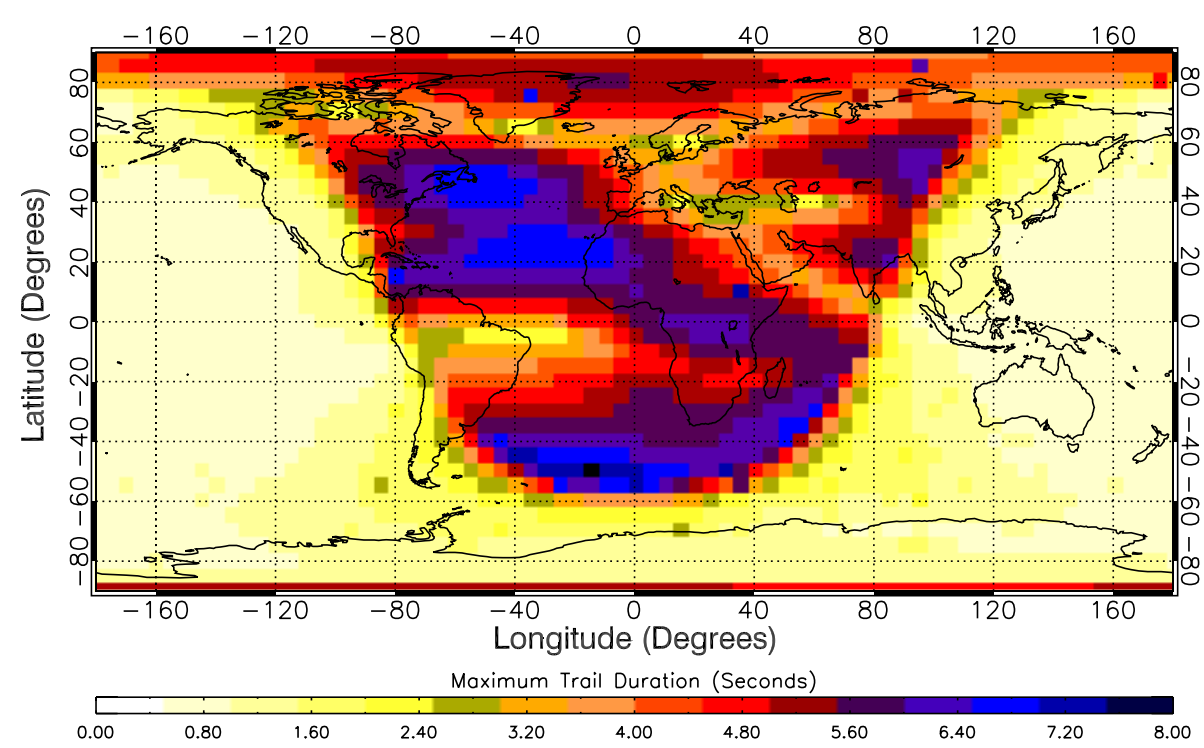

Fig. 4. A global simulation of the duration of meteor trail turbulence of a single $1 \mu$ g meteor simulated globally with $5^{\circ}$ grid points, traveling at $35 \mathrm{~km} \mathrm{~s}^{-1}$ with an entry angle of $45^{\circ}$ at 00:00 UT on 1 January. The units of the color bar are in seconds after meteor trail creation. Each pixel results from the measured duration of a simulation of the type shown in Fig. 1. This $35 \mathrm{~km} \mathrm{~s}^{-1}$ case provides an interesting comparison with Fig. $2 b$, which has a speed of $55 \mathrm{~km} \mathrm{~s}^{-1}$. This simulated meteor traveling at $35 \mathrm{~km} \mathrm{~s}^{-1}$ has a preferred velocity for producing a long duration meteor trail. Not only are longer duration trails produced, but there are also trails in areas where they were absent or short lived in Fig. 2b.

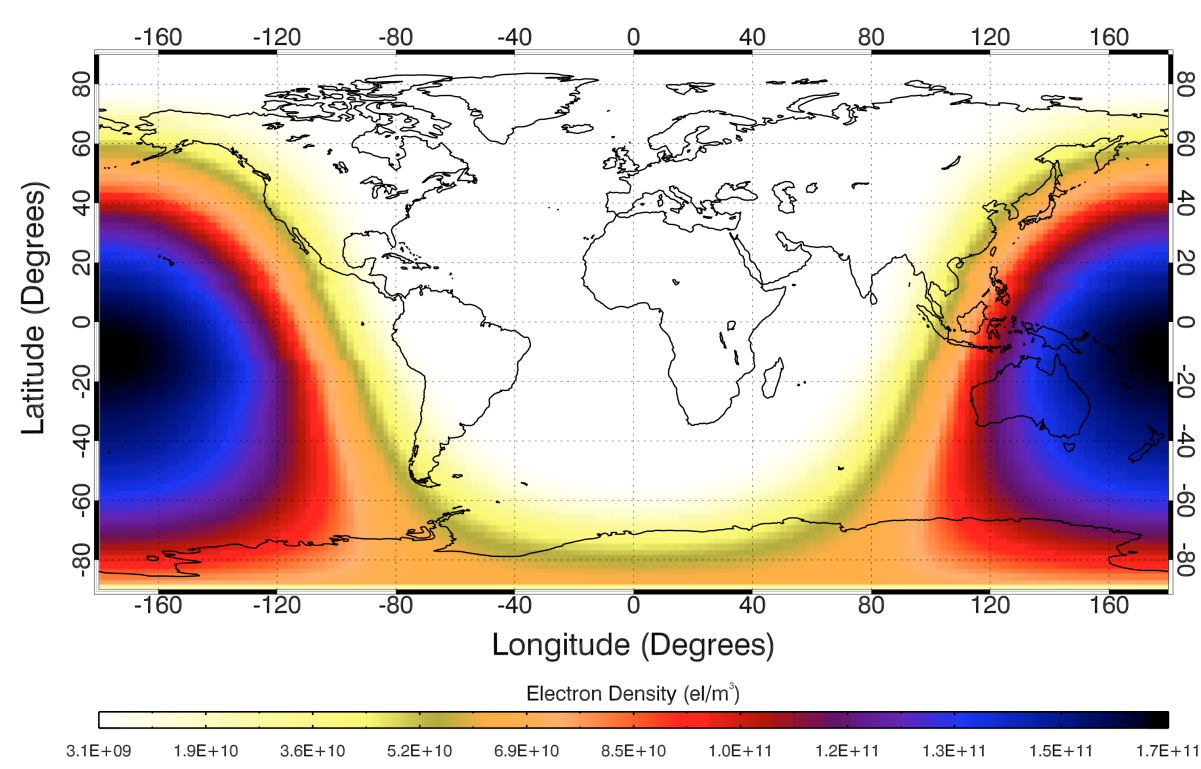

Fig. 5. The global structure of electron density in the Earth's ionosphere is plotted at an altitude of $100 \mathrm{~km}$ for the simulated cases shown in Fig. 2a and b. Density is measured in $\mathrm{m}^{-3}$ at 00:00 UT on 1 January. The color bar shows densities that range from high density present during daytime hours to the low densities present at night. Notice the distinct diurnal cycle of high daytime density located at the east/west of the map and the low nighttime density area located at the center of the map. Note that higher electron density inhibits meteor trail evolution.

\section{Discussion}

This paper presents a dramatic global and seasonal variability in meteor trail evolution. We find that variations in trail turbulence duration are caused by two main atmospheric prop- erties: electron density of the ionosphere and the magnitude of horizontal winds. While the observational studies of meteor trail turbulence and non-specular meteor trails remain sparse based on geographical and local time coverage, several observational trends have been reported in the literature 
(Sugar et al., 2010). The model we constructed is useful for placing data from individual sites into the context of a global meteor flux based upon local atmosphere and ionosphere observing conditions. Here we review some observations on diurnal trends.

Chapin and Kudeki (1994a, b) published some of the first observations of non-specular trails from the Jicamarca radar. While it was not the focus of their paper, the difference in trail occurrence and duration before and after sunrise was clearly shown in their Fig. 4. The figure shows two distinct periods of meteor observations; the first half contains over 125 meteor echoes before sunrise near 06:20 LT, followed by an abrupt decrease in the number trails observed. After 06:20 LT only 20 meteor echoes are seen throughout the second half of the observation.

Recently, Oppenheim et al. (2008) drew specific attention to the diurnal variability of non-specular echoes at Jicamarca. Before dawn, 341 non-specular trails were observed for 1288 head echoes and only 81 trails for 1240 head echoes after dawn. They suggested that this was evidence of a previously published theory by Dimant and Oppenheim (2006a, b) that predicted stronger internally generated zeroth order ambipolar fields at night, and therefore an enhanced driver for instabilities. In contrast, we provide an alternative explanation for this day night variability based on the results presented herein: In addition to background electron density, the presence of background electric fields resulting from electrojets or winds drive polarization fields that dominate the ambipolar fields within the meteor trail (see Dyrud et al., 2007).

Zhou et al. (2001) presented observations of head echoes and non-specular trials from the MU $50 \mathrm{MHz}$ radar in Japan. This experiment was conducted with the radar pointing both perpendicular, and off perpendicular to the geomagnetic field. They noted that essentially all head echoes had a corresponding non-specular trail in the perpendicular to $\boldsymbol{B}$ geometry, while the off perpendicular had essentially no trails, but similar counts of head echoes. Their data were collected from 00:00 to 08:30 LT over 4 nights, but made no comment on pre and post sunrise differences. These results cemented the view that non-specular echoes result from plasma instability induced field aligned irregularities (FAI). While not the primary focus, Close et al. (2008) recently demonstrated that larger meteoroids are more likely to produce non-specular echoes than those that are smaller.

Simek (1995) examined the seasonal and diurnal variability of specular meteor trail durations and showed that mean sunlit durations were $2.27 \pm 0.11 \mathrm{~s}$, but that night durations were $1.97 \pm 0.06 \mathrm{~s}$. Although the observational differences were relatively small, these general trends fit what we expect and report herein. That is, enhanced diffusion due to trail turbulence during predominantly nighttime conditions reduces meteor trail duration. However, the durations reported here include a number of additional factors that influence duration such as changing echo altitude as a function of local time. However, specular echo duration as a function of al-

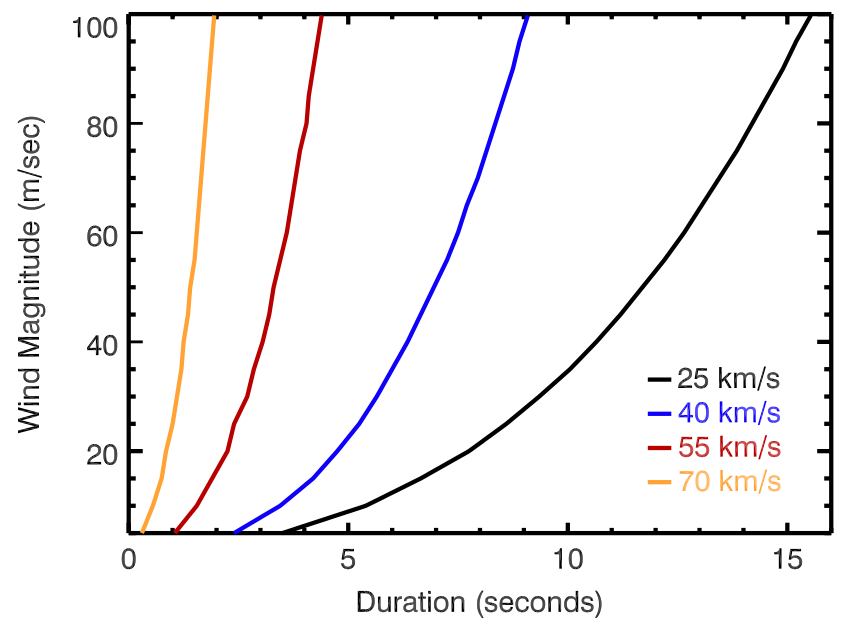

Fig. 6. A plot of trail duration versus wind speed for the cases of 4 different velocities and a $1.0 \mu \mathrm{g}$ meteor with $0^{\circ}$ entry angle. Notice the influence that an increased magnitude in horizontal wind speeds has on a meteor's plasma trail and its duration. The plot used data from simulations of the meteor trail durations of 4 identical meteors traveling at different speeds: $25 \mathrm{~km} \mathrm{~s}^{-1}, 40 \mathrm{~km} \mathrm{~s}^{-1}, 55 \mathrm{~km} \mathrm{~s}^{-1}$ and $70 \mathrm{~km} \mathrm{~s}^{-1}$. Each of the meteors is simulated at different wind speeds. Note that meteor trail duration is directly linked to the magnitude of the wind speed.

titude, which helps to isolate the effects of trail turbulence, has been examined by Singer et al. (2008). They showed that low altitude decay times decreased at high latitude in summer. In addition, they showed that strong echoes from trails had longer decay times than weaker echoes (stronger echoes likely typify higher electron line densities produced by larger meteoroids). However, examination of this author's Fig. 2 shows that these trends are reversed near the highest altitude of observation $(94 \mathrm{~km})$. The results reported here explain this seasonal and meteor size trend reversal at higher altitudes. In the summer hemisphere trails are more likely to be produced in a sunlit ionosphere, and therefore remain turbulent for shorter periods of time or not at all. If turbulent decay rates are faster than laminar decay rates as reported by Dyrud et al. (2001) we expect summer trails to possess, on average, longer decay times. Since larger meteoroids produce larger plasma density gradients we also expect larger trails (or stronger echoes) to possess faster decay times. Further, these effects of turbulent diffusion are more pronounced at higher altitude as also discussed by Dyrud et al. (2001).

In a study of specular trail diffusion as a function of radar pointing to $\boldsymbol{B}$, Hocking (2004) suggested "... future theoretical analysis need to include externally imposed electric fields in order to produce accurate simulations of diffusion rates..." This is exactly what we have included in this study. Hocking (2004) examined decay times as a function of radar azimuth angle and time of day, and found that there was far stronger anisotropic diffusion at greater altitudes above 


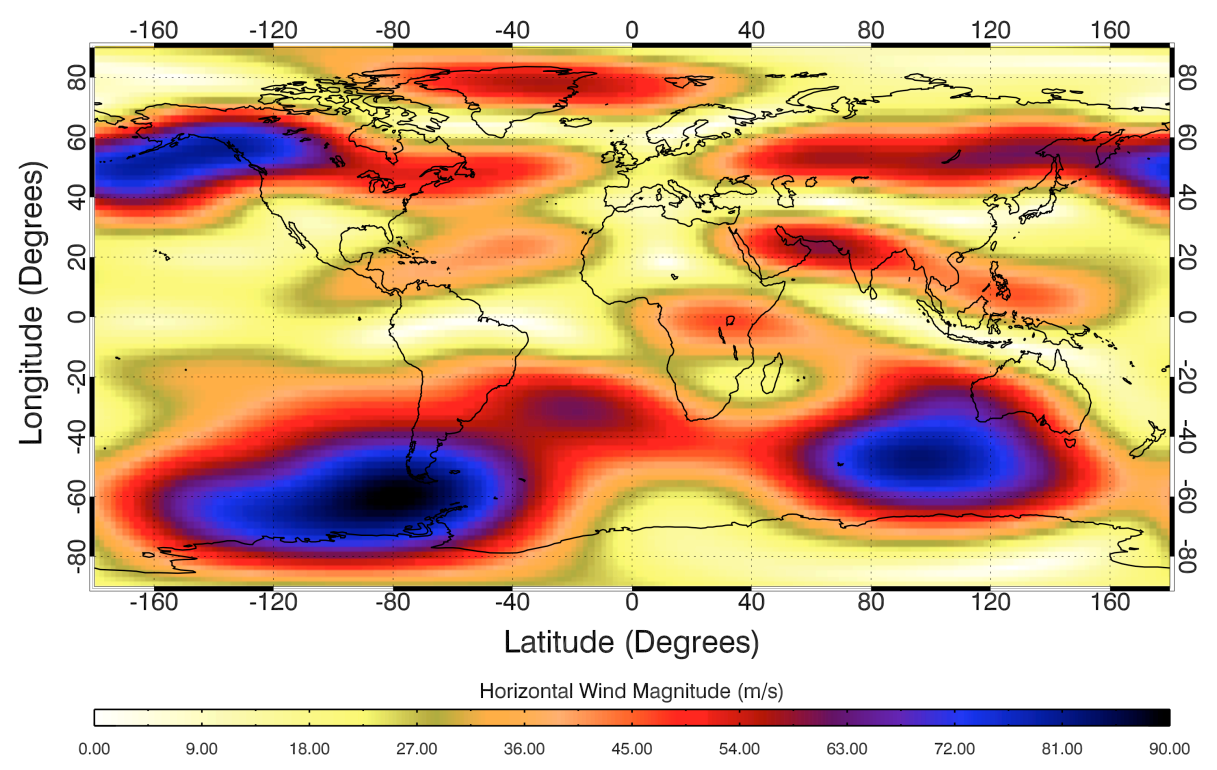

Fig. 7. A global plot of the magnitude of horizontal wind speed present on 1 January at 00:00 UT at $100 \mathrm{~km}$ in Fig. 2a and b. The color bar shows wind speed in $\mathrm{m} \mathrm{s}^{-1}$. The wind pattern shown here is present throughout the day and is fixed in local time. Notice the large variations in the magnitude of horizontal wind speed and its geographic distribution, which effects trail evolution.

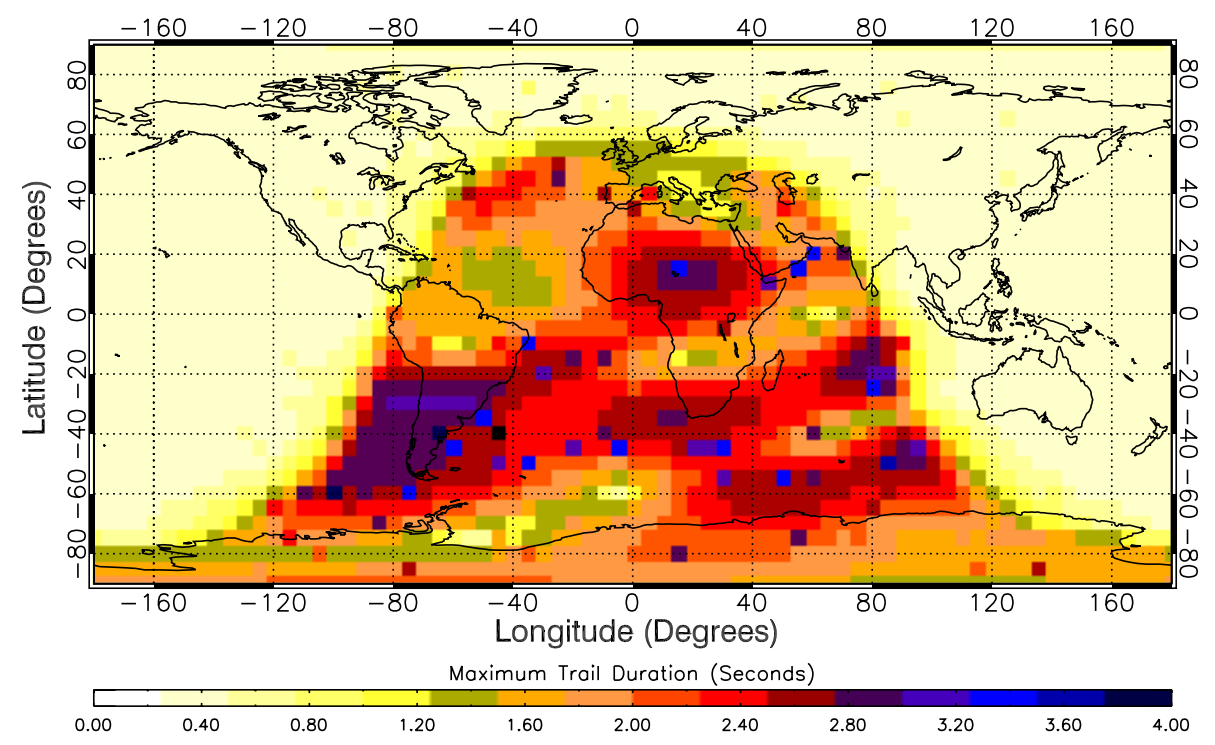

Fig. 8. A global snapshot of the meteors' trail duration, measured in seconds, is plotted above. This simulation for a $1 \mu \mathrm{g}$ meteor traveling at $55 \mathrm{~km} \mathrm{~s}^{-1}$ with an entry angle of $45^{\circ}$ on 27 June at 00:00 UT. The units of the color bar are in seconds after meteor trail creation. The simulated meteor is identical to Fig. $2 \mathrm{~b}$ with the exception of the date. Notice the differences in the global structure of trail duration compared to Fig. $2 b$, which is simulated on 1 January. The differences are caused by the changes in the atmosphere throughout the seasons; namely the structure of electron density and the magnitude of the horizontal wind.

$93 \mathrm{~km}$, and that winds and electric fields appear to influence the diffusion rate in general, and the overall anisotropy.

As the above summary of studies show, the existing nonspecular and specular trial observations do support a day to night variation in the occurrence of meteor trail plasma turbulence. The studies also show that larger meteoroids are more likely to produce turbulent trails. Further, our simula- tions here indicate that this day/night occurrence variation is one that is predicted to be global. However, the detailed variability is a result of the altitude dependent magnitude of wind profiles. Understanding this variability will require substantially increased observations, both in terms of geographical and local time coverage, and comparison with data from other instruments. We conclude by noting that the driving 
factors accounting for meteor trail turbulence are many, complex and interrelated, thus it is not the focus of this short letter to describe all the competing forces but to publicize the predicted dramatic variability to researchers in various meteor related fields. We are working on a detailed analysis of the various contributions and expect to report them in an upcoming publication, but can summarize the general trends here:

1. The primary drivers for turbulence duration are background ionization: turbulence lasts longer at night;

2. Wind or drift velocity: higher winds or drifts produce longer turbulent durations;

3. Meteoroid mass: larger meteoroids produce longer turbulent durations;

4. Velocity: velocities near $35 \mathrm{~km} \mathrm{~s}^{-1}$ (with some modification with entry angle and a particular mass) produce longer lasting turbulence because they deposit their mass at preferred altitudes for turbulence, between 90-105 km altitude.

We expect that a more complete understanding and characterization of all the driving forces behind meteor trail turbulence will improve our knowledge of non-specular trails, but also dramatically improve our ability to use specular trail observations to derive atmospheric temperature and other parameters, by isolating decay rates from the influence of turbulence.

Acknowledgements. Lars Dyrud and Jonathan Fentzke were supported by NSF grants ATM-0613706 and ATM-0638912. Julio Urbina, Jason Hinrichs and Elias Hibbit's work was supported by NSF grants ATM-0638624 and ATM-0457156 to Penn State University.

Topical Editor K. Kauristie thanks A. K. Pellinen-Wannberg and another anonymous referee for their help in evaluating this paper.

\section{References}

Banks, P. M. and Kockarts, G.: Aeronomy: Part A, Chapter 9, Academic Press, 1973.

Bilitza, D.: International Reference Ionosphere 2000, Radio Sci., 36, 261-275, 2001.

Ceplecha, Z., Borovička, J., Elford, W., Revelle, D., Hawkes, R., Porubčan, V., and Šimek, M.: Meteor Phenomena and Bodies, Space Sci. Rev., 84, 327-471, 1998.

Cervera, M. A. and Elford, W. G.: The meteor radar response function: Theory and application to narrow beam MST radar, Planet. Space Sci., 52, 591-602, 2004.

Chapin, E. and Kudeki, E.: Radar interferometric imaging studies of long duration meteor echo observed at Jicamarca, J. Geophys. Res., 99, 8937-8949, 1994a.

Chapin, E. and Kudeki, E.: Plasma-wave excitation on meteor trails in the equatorial electrojet, Geophys. Res. Lett., 21, 2433-2436, 1994b.
Chau, J. L. and Galindo, F.: First definitive observations of meteor shower particles using a high-power large-aperture radar, Icarus, 194, 23-29, 2008.

Chau, J. L., Woodman, R. F., and Galindo, F.: Sporadic meteor sources as observed by the Jicamarca high-power large-aperture VHF radar, Icarus, 188, 162-174, 2007.

Close, S., Oppenheim, M., Hunt, S. M., Dyrud, L. P.: Scattering characteristics of high-resolution meteor head echoes detected at multiple frequencies, J. Geophys. Res. (Space Physics), 107, A10, doi:10.1029/2002JA009253, 2002.

Close, S., Hamlin, T., Oppenheim, M., Cox, L., and Colestock, P.: Dependence of radar signal strength on frequency and aspect angle of nonspecular meteor trails, J. Geophys. Res., 113, A06203, doi:10.1029/2007JA012647, 2008.

Committee on Space Research (COSPAR): The COSPAR International Reference Atmosphere (CIRA-05), [Internet]. British Atmospheric Data Centre, available from: http://badc.nerc.ac.uk/ data/cira/, 2006.

Dimant, Y. S. and Oppenheim, M. M.: Meteor trail diffusion and fields: 2. Analytical theory, J. Geophys. Res., 111, A12313, doi:10.1029/2006JA011798, 2006a.

Dimant, Y. S. and Oppenheim, M. M.: Meteor trail diffusion and fields: 1. Simulations, J. Geophys. Res., 111, A12312, doi:10.1029/2006JA011797, 2006b.

Dyrud, L. P. and Janches, D.: Modeling the meteor head echo using Arecibo radar observations, J. Atmos. Solar-Terr. Phys., 70, 1621-1632, 2008.

Dyrud, L. P., Oppenheim, M. M., and vom Endt, A. F.: The Anomalous Diffusion of Meteor Trails, Geophys. Res. Lett., 28, 27752778, 2001.

Dyrud, L. P., Oppenheim, M. M., Close, S., and Hunt, S.: Interpretation of Non-Specular Radar Meteor Trails, Geophys. Res. Lett., 29, 21, 8-1 - 8-4, doi:10.1029/2002GL015953, 2002.

Dyrud, L., Denney, K., Urbina, J., Janches, D., Kudeki, E., and Franke, S.: The meteor flux: it depends how you look, Earth, Moon Planets, 95, 89-100, doi:10.1007/s11038-005-9001-6, 2005a.

Dyrud, L. P., Kudeki, E., and Oppenheim, M. M.: Modeling long duration meteor trails, J. Geophys. Res., 112, A12307, doi:10.1029/2007JA012692, 2005b.

Dyrud, L. P., Kudeki, E., and Oppenheim, M. M.: Modeling long duration meteor trails, J. Geophys. Res., 112, A12307, doi:10.1029/2007JA012692, 2007.

Dyrud, L. P., Wilson, D., Boerve, S., Trulsen, J., Pecseli, H., Close, S., Chen, C., and Lee, Y.: Plasma and Electromagnetic Simulations of Meteors, Adv. Space Res., 42, 1,136-142, doi:10.1016/j.asr.2007.03.048, 2008.

Fentzke, J. T. and Janches, D.: A semi-empirical model of the contribution from sporadic meteoroid sources on the meteor input function in the MLT observed at Arecibo, J. Geophys. Res., 113, A03304, doi:10.1029/2007JA012531, 2008.

Fukuda, A., Mukumoto, K., Yoshihiro, Y., Nagasawa, M., Yamagishi, Y., Sato, N., Yang, H., Yao, M. W., and Jin, L. J.: Experiments on meteor burst communications in the Antarctic, Adv. Polar Upper Atmos. Res., 17, 120-136, 2003.

Galligan, D. P., Thomas, G. E., and Baggaley, W. J.: On the relationship between meteor height and ambipolar diffusion, J. Atmos. Solar-Terr. Phys., 66, 899-906, 2004.

Hedin, A. E., Fleming, E. L., Manson, A. H., Schmidlin, F. J., Av- 
ery, S. K., Clark, R. R., Franke, S. J., Fraser, G. J., Tsuda, T., Vial, F., and Vincent, R. A.: Empirical wind model for the middle and lower atmosphere. J. Atmos. Terr. Phys., 58, 1421-1447, 1996.

Hibit, E.: The role of atmospheric parameters and turbulence on meteor trail evolution: analysis and simulations, MS thesis, The Pennsylvania State University, University Park, PA, USA, 2010.

Hinrichs, J., Dyrud, L. P., and Urbina, J.: Diurnal variation of non-specular meteor trails, Ann. Geophys., 27, 1961-1967, doi:10.5194/angeo-27-1961-2009, 2009.

Hocking, W. K.: Temperatures Using Radar-Meteor Decay Times., Geophys. Res. Lett., 26, 21, 3297-3300, doi:10.1029/1999GL003618, 1999.

Hocking, W. K.: Experimental Radar Studies Of Anisotropic Diffusion Of High Altitude Meteor Trails., Earth, Moon, Planets, 95, 671-679, 2004.

Janches, D., Mathews, J. D., Meisel, D. D., and Zhou, Q. H.: Micrometeor Observations Using the Arecibo $430 \mathrm{MHz}$ Radar: I. determination of the ballistic parameter from measured Doppler velocity and deceleration results, Icarus, 145, 53-63, doi:10.1006/icar.1999.6330, 2000.

Janches, D., Heinselman, C. J., Chau, J. L., Chandran, A., and Woodman, R.: Modeling the global micrometeor input function in the upper atmosphere observed by high power and large aperture radars, J. Geophys. Res., 111, A07317, doi:10.1029/2006JA011628, 2006.

Kumar, K.: Temperature profiles in the MLT region using radar-meteor trail decay times: Comparison with TIMED/SABER observations, Geophys. Res. Lett., 34, 16, L16811, doi:10.1029/2006JA011628, 2007.

Malhotra, A., Mathews, J. D., and Urbina, J.: Multi-static, common volume radar observations of meteors at Jicamarca, Geophys. Res. Lett., 34, L24103, doi:10.1029/2007GL032104, 2007a.

Malhotra, A., Mathews, J., and Urbina, J.: A radio science perspective on long-duration meteor trails, J. Geophys. Res., 112, A12303, doi:10.1029/2007JA012576, 2007b.
Mathews, J. D., Janches, D., Meisel, D., and Zhou, Q.: The micrometeoroid mass flux into the upper atmosphere: Arecibo results and a comparison with prior estimates, Geophys. Res. Lett., 28,10, 1929-1932, doi:10.1029/2000GL012621, 2001.

Oppenheim, M. M., vom Endt, A. F., and Dyrud, L. P.: Electrodynamics of Meteor Trail Evolution in the Equatorial E-Region Ionosphere, Geophys. Res. Lett., 27, 3173-3176, 2000.

Oppenheim, M. M., Dyrud, L. P., and Ray, L.: Plasma instabilities in meteor trails: Linear theory, J. Geophys. Res., 108, 1063, doi:10.1029/2002JA009548, 2003a.

Oppenheim, M. M., Dyrud, L. P., and vom Endt, A. F.: Plasma instabilities in meteor trails: 2-D simulation studies, J. Geophys. Res., 108, 1064, doi:10.1029/2002JA009549, 2003b.

Oppenheim, M. M., Sugar, G., Bass, E., Dimant, Y. S., and Chau, J.: Day to night variation in meteor trail measurements: Evidence for a new theory of plasma trail evolution, Geophys. Res. Lett., 35, L03102, doi:10.1029/2007GL032347, 2008.

Simek, M.: Diurnal and seasonal variations of sporadic meteor parameters, Earth, Moon, Planets, 68, 545-553, 1995.

Singer, W., Latteck, R., Millan, L. F., Mitchell, N. J., and Fiedler, J.: Radar Backscatter from Underdense Meteors and Diffusion Rates, Earth Moon Planet, 102, 403-409, doi:10.1007/s11038007-9220-0, 2008.

Sugar, G., Oppenheim, M., Bass, E., and Chau, J.: Nonspecular meteor trail altitude distributions and durations observed by a $50 \mathrm{MHz}$ high-power radar, J. Geophys. Res., 115, A12334, doi:10.1029/2010JA015705, 2010.

Urbina, J., Kudeki, E., Franke, S. J., Gonzales, S., Zhou, Q., and Collins, S. C.: $50 \mathrm{MHz}$ radar observations of mid-latitude Eregion irregularities at Camp Santiago, Puerto Rico, Geophys. Res. Lett., 27, 2853-2856, doi:10.1029/2000GL000028, 2000.

Zhou, Q. H., Mathews, J. D., and Nakamura, T.: Implications of Meteor Observations by the MU Radar, Geophys. Res. Lett., 28, 1399-1402, doi:10.1029/2000GL012504, 2001. 